\title{
DIREITOS HUMANOS E O PLANO DE VALIDADE NA TEORIA DO FATO JURÍDICO DE PONTES DE MIRANDA: UMA ANÁLISE A PARTIR DOS TRATADOS DE DIREITOS HUMANOS RATIFICADOS PELO BRASIL
}

\section{HUMAN RIGHTS AND THE VALIDITY PLAN IN THEORY OF LEGAL FACT PONTES DE MIRANDA: AN ANALYSIS FROM THE HUMAN RIGHTS TREATIES RATIFIED BY BRAZIL}

WILSON ENGELMANN

Pós-doutor en los Retos Actuales del Derecho Público, organizado pelo Centro de Estudios de Seguridad de la Universidad de Santiago de Compostela, Espanha, sob a supervisão do Prof. Dr. José Julio Fernández Rodríguez; graduação em Direito (1988). Doutorado em Direito Público (2005), todos esses níveis de formação pela Universidade do Vale do Rio dos Sinos - UNISINOS. Coordenador Executivo do Mestrado Profissional em Direito da Empresa e dos Negócios da Unisinos; professor e pesquisador do Programa de Pós-Graduação em Direito - Mestrado e Doutorado da Unisinos.

ALINE ANDRIGHETTO Mestrado em Direito pela Universidade Regional Integrada do Alto Uruguai e das Missões, Brasil(2013). Professor do Centro Universitário CNEC Osório, Brasil.

\section{RESUMO}

O presente artigo propõe-se a definir os elementos constitutivos dos Tratados sobre Direito Humanos albergados pela noção de regra jurídica e os planos desenhados por Francisco Cavalcanti Pontes de Miranda. Verifica de que maneira ocorre a previsão 
de proteção via legislação Constitucional de grupos minoritários ao incorporarem os Planos de validade e eficácia de Pontes de Miranda. Procura ainda, a partir do estudo da Teoria das Fontes do Direito analisar de que modo o diálogo entre as fontes atua de maneira sistemática a qual se perfaz o mundo jurídico abrindo possibilidades para a valorização de outras formas de expressão jurídica como o estudo sobre as decisões da Corte Interamericana de Direitos e a Convenção Americana de Direitos Humanos. Objetiva este artigo verificar de que maneira e se há previsão de proteção via legislação Constitucional de grupos minoritários ao incorporarem os Planos de validade e eficácia de Pontes de Miranda. Ainda, como se dará frente às desigualdades sociais enfrentadas no século XXI pelos diversos fatores sociais. $\mathrm{O}$ trabalho será orientado pelo método fenomenológico- hermenêutico a partir de bibliografia específica.

PALAVRAS-CHAVE: Direitos Humanos; Plano de Validade; Fato Jurídico; Tratados.

\section{ABSTRACT}

This article proposes to define the constituent elements of the Treaties on Human Rights harbored the notion of rule of law and the plans designed by Francisco Cavalcanti Pontes de Miranda. Checks how occurs Constitutional law via protection forecasting minority groups to incorporate Plans validity and Pontes de Miranda effectiveness. It also seeks, from the study of law sources of theory to analyze how the dialogue between sources operates in a systematic way which is amounts to the legal world opening up possibilities for the recovery of other forms of legal expression as the study of decisions the Inter-American Court of rights and the American Convention on Human rights. This article aims to verify how and whether there is constitutional protection legislation via prediction minority groups to incorporate Plans validity and Miranda Bridges effectiveness. Still, how it will face the social inequalities faced in the twenty-first century by many social factors. The work will be guided by the hermeneutic phenomenological method from specific bibliography. 
KEYWORDS: Human Rights; Plan Validity; Legal fact; Treaties.

\section{INTRODUÇÃO}

Este artigo propõe-se a definir quais os elementos constitutivos dos Tratados sobre Direito Humanos, a fim de serem albergados pela noção de "regra jurídica" e os diversos planos desenhados por Francisco Cavalcanti Pontes de Miranda.

A obra de Pontes de Miranda obedece um programa rigorosamente científico: a distinção entre mundo fático e mundo jurídico, que é o do sistema jurídico, vem à frente, e concorre imensamente para clarear os assuntos e para a solução de problemas delicados que perturbavam a ciência européia; depois, a distinção entre o plano da existência, o plano da validade e o plano da eficácia, sem a qual em tantas confusões incorrem os juristas. A ciência do direito, colhendo das regras jurídicas, da sistemática e da prática dos conceitos, obedece às diferenças: os juristas, aqui e ali, perdem-nas de vista.

Sobre a incidência e aplicação do Direito diz-se que é falsa qualquer teoria que considere apenas provável ou suscetível de não ocorrer a incidência das regras jurídicas, mas é essencial a todo estudo sério do direito considerar-se, em ordem. Sobre o suporte fático, a que se refere, ainda, a incidência resulta a eficácia do fato jurídico, isto é, as relações jurídicas e mais efeitos dos fatos jurídicos. Com isso, fatos Jurídicos e eficácia jurídica no direito, com a dose de elemento estabilizador que o caracteriza, ou promete que o que é, juridicamente, continuará de ser, ou que produzirá tais e tais efeitos.

Segundo Pontes, todo fato é, pois, mudança no mundo. O mundo compõe-se de fatos, em que novos fatos se dão. O mundo jurídico compõe-se de fatos jurídicos. Os fatos, que se passam no mundo jurídico, passam-se no mundo; portanto: são. Com isso, há pretensão neste artigo, de realizar o estudo da Teoria das Fontes do Direito a fim de ser verificado o diálogo entre normas jurídicas. A partir desta ideia, uma análise da Teoria do Fato Jurídico não poderá apresentar apenas uma 
perspectiva, mas abrir possibilidades para a valorização de outras formas de expressão jurídica.

Quanto às fontes do Direito podem ser consideradas as materiais, as quais incluem fatores sociológicos, econômicos e culturais, os quais conduzem a instituição da norma jurídica; e formais, regras jurídicas elaboradas por processo legislativo, costumes, analogia e princípios do Direito. Os tratados são considerados fontes externas e neles encontram-se os costumes, a doutrina e a jurisprudência.

A concepção contemporânea de direitos humanos conjuga liberdade e igualdade, no sentido de decorrerem de direitos concebidos como uma unidade interdependente e indivisível, em decorrência, não há como entender que há uma sucessão de fatos sociais e há uma interação de direitos. Para Piovesan, o Direito Internacional dos Direitos Humanos consiste em um sistema de normas, procedimentos e instituições internacionais desenvolvidos para implementar esta concepção e promover o respeito dos direitos humanos em todos os países, no âmbito mundial (2014, p.72). Assim, pode-se afirmar que a normatividade internacional de proteção dos direitos humanos, conquistada através de incessantes lutas históricas foi fruto de um lento processo gradual de internacionalização e universalização de direitos.

Pretende-se por fim, demonstrar a legalidade de direitos provenientes da ordem jurídica internacional, contidos na Declaração Universal dos Direitos do Homem (1948), nos pactos que a regulamentaram, especialmente na Convenção Americana de Direitos Humanos, chamada de Pacto de San José da Costa Rica (CADH), demonstrando alguns julgados da Corte Interamericana.

O objetivo do artigo é verificar como, e se há previsão de proteção via legislação Constitucional de grupos minoritários ao incorporarem os Planos de validade e eficácia de Pontes de Miranda. Se houver, como se dará frente às desigualdades sociais enfrentadas no século XXI pelos diversos fatores sociais.

O trabalho será orientado pelo método fenomenológico- hermenêutico desenvolvido por Hans- Georg Gadamer e Martin Heidegger, com base na literatura de Pontes de Miranda e Direitos Humanos. 


\section{PLANOS DA EXISTÊnCIA, VALIDADE E EFICÁCIA PARA PONTES DE MIRANDA}

O estudo de Pontes de Miranda provém de uma análise da Ciência do Direito, o qual verifica cientificamente os problemas fundamentais da causalidade, liberdade, espaço- tempo social e outras variáveis. Desenvolve criteriosa crítica da explicação e elaboração do Direito, além de deter-se na evolução moderna filosofia social, com a apreciação rigorosa das teorias político-sociais, ora do individualismo, quer do socialismo. Ainda versa o estudo sobre os elementos lógicos da lei, ocupando-se do conceito, da palavra, das fórmulas, das definições e dos julgamentos, com a definição dos perigos do raciocínio dedutivo. Para Engelmann, "o pano de fundo que sustenta a obra, decorrente do momento histórico em que foi produzida, ou seja, pouco antes da metade do Século XX, é fortemente influenciado pelo positivismo jurídico, notadamente na sua vertente legalista" (2011, p.1).

O Tratado de Direito Privado de Pontes de Miranda, coloca que os sistemas jurídicos são sistemas lógicos, compostos de preposições que se referem a situações da vida, criadas pelos interesses mais diversos. Essas preposições, regras jurídicas, prevêem situações ocorrem, e incidem sobre elas, como se as marcassem. Para quem está no mundo em que elas operam, as regras jurídicas marcam, dizem o que se há de considerar jurídico e, por exclusão, o que se não há de considerar jurídico. A função social do direito é dar valores a interesses, a bens da vida, e regular-Ihes a distribuição entre os homens. Comenta Engelmann que "a logicidade do sistema jurídico encontra respaldo na característica de inexistência de contradição, pois ao Direito cabe apreender o fato social e compará-lo às regras existentes na configuração do mundo jurídico" (2011, p.3).

O jurista, no entendimento de Pontes, é o especialista em conhecimentos das regras jurídicas e da interpretação delas. Segundo ele, para chegar a essa especialização e ser fecunda, leal, exata, a sua função, torna-se necessário conhecer o passado do sistema jurídico e, de cada regra jurídica, assim como o sistema jurídico do seu tempo, pois no momento em que pensa, ou pensa e fala ou escreve, há uma atuação diferenciada do sistema jurídico. O sistema jurídico contém regras jurídicas e 
essas se formulam com os conceitos jurídicos. Nesse sentido, tem-se que estudar o fático, isto é, as relações humanas e os fatos, a que elas se referem, para se saber qual o suporte fático, isto é, aquilo sobre que elas incide apontado por elas. Segundo ele "[...] interpretar leis é lê-las, entender-Ihes e criticar-Ihes o texto e revelar-Ihes o conteúdo"(MIRANDA, 1954a, p.XII).

Repensando a noção fundamental do direito com base em Pontes de Miranda, diz-se que é a de fato jurídico depois a de relação jurídica. Só há direitos subjetivos porque há sujeitos de direito, e só há sujeitos de direito porque há relações jurídicas. O grande trabalho da ciência jurídica tem sido o de examinar o que é que verdadeiramente se passa entre homens, quando se dizem credores, titulares ou sujeitos passivos de obrigações.

O pensamento de Pontes de Miranda obedece a um critério rigorosamente científico onde a distinção entre mundo fático e mundo jurídico, que é o do sistema jurídico, vem à frente, e concorre imensamente para clarear os assuntos e para a solução de problemas delicados que perturbaram a ciência durante muito tempo. A distinção entre o plano da existência, o plano da validade e o plano da eficácia, sem a qual em tantas confusões incorrem os juristas, baralhando "ser", "valer" e "ter feito", como se fossem equivalentes "ser", "ser válido", "ser eficaz", ou "não ser", "não ser válido", "ser ineficaz" foi muito importante e continua permeando o pensamento dos juristas no sentido de fazer entender e redescobrir se a ciência do direito, colhendo das regras jurídicas, da sistemática e da prática dos conceitos.

Os conceitos de Regra Jurídica e suporte fático desenvolvido por Pontes asseveram que a regra jurídica é norma com que o homem, ao querer subordinar os fatos a certa ordem e a certa previsibilidade, procurou distribuir os bens da vida (MIRANDA, 1.954 a, p.3). Sobre sua incidência e aplicação diz-se que é falsa qualquer teoria que considere apenas provável ou suscetível de não ocorrer.

Com relação à incidência da regra jurídica, sua eficácia não se confunde com ela, nem com a eficácia do fato jurídico, a eficácia da regra jurídica é a sua incidência, a do fato jurídico irradia-se, é juridicialização das consequências dele, devido à incidência. "A causalidade, no jurídico, prende-se à estrutura do pensamento humano 
e à sua descoberta de poder adotar, para os fatos, regras que incidam" (MIRANDA, 1954a, p. 18).

A respeito do suporte fático da regra jurídica, aquele fato, ou grupo de fatos que compõe, e sobre o qual a regra jurídica incide, afirma-se que o suporte fático ainda está no mundo fático; a regra jurídica colore-o, fazendo-o entrar no mundo jurídico. Ato jurídico não é regra jurídica. Passa-se com os atos jurídicos o mesmo que com os demais fatos jurídicos (MIRANDA, 1954a, p.19).

O mesmo fato ou complexo de fatos pode ser suporte de mais de uma regra jurídica. Então as regras jurídicas incidem e fazem-no fato jurídico de cada uma delas, com a sua respectiva irradiação de eficácia. Se, no mesmo Estado, o mesmo fato é suporte de duas ou mais regras jurídicas, cada uma incide; e do fato jurídico produzido irradiam-se os efeitos respectivos, salvo se outro elemento do suporte faz só uma ter de incidir. Fato jurídico então é o suporte fático que o direito reputou pertencer ao mundo jurídico. A entrada dele nesse mundo, e não a sua permanência eficaz é que o pode definir.

Pontes faz uma divisão de matérias em sua obra a partir de uma ordem lógicocientífica. Primeiro expõe o que concerne ao plano da existência, depois, o que se refere ao plano da validade, finalmente, o que refere ao plano da eficácia. $O$ fato jurídico primeiro é; se é, e somente se é, pode ser válido, nulo, anulável, rescindível, resolúvel, etc; se é, e somente se é, pode irradiar efeitos, posto que haja fatos jurídicos que não os irradiam, ou ainda não os irradiam (1954, p.XX).

Para que algo tenha valor é necessário que exista, pois não há sentido falar de validade a respeito do que não existe. Existência é questão prévia, pois somente depois de se afirmar que existe é que é possível pensar em Validade. Segundo Miranda, os conceitos de validade ou de invalidade só se referem a atos jurídicos, isto é, a atos humanos que entraram (plano da existência) no mundo jurídico e se tornaram atos jurídicos (MIRANDA, 2000).

Quando se fala de fatos alude-se a algo que ocorreu, ocorre ou vai ocorrer, com isso, o direito com a dose de elemento estabilizador que o caracteriza ou promete que o é, juridicamente, continuará a ser, ou produzir tais e tais efeitos. Eficácia jurídica 
é o que se produz no mundo do direito em decorrência dos fatos jurídicos e não, a mudança que atua nas relações jurídicas. Os elementos do suporte fático são pressupostos do fato jurídico, o fato que entra do suporte fático, no mundo jurídico, mediante a incidência da regra jurídica sobre o suporte, ou seja, só de fatos jurídicos provém eficácia jurídica. O suporte fático da regra jurídica é aquele fato, ou grupo de fatos que o compõe, e sobre o qual a regra jurídica incide.

Para que o ato jurídico possa valer, é preciso que o mundo jurídico o tenha por apto a nele atuar e permanecer, é aqui que ele vai exigir eficiência e por aqui é que seus efeitos terão de irradiar (eficácia) (MIRANDA, 2000, p. 35).

Somente o fato que esteja regulado por norma jurídica pode ser considerado um fato jurídico, ou seja, um fato gerador de direitos, deveres, pretensões, obrigações ou qualquer outro efeito jurídico. Somente o fato previsto em suporte fático de um texto legal poderá receber, por subsunção, os efeitos decorrentes da juridicização do fato. Por isso, os princípios não cabem na estrutura da regra jurídica planejada por Pontes de Miranda (ENGELMANN, 2012).

Cabe lembrar que Pontes de Miranda, ao construir seu sistema de ciência positiva do direito utilizou categorias pertencentes à sociologia, onde desenvolve etapas referentes à aquisição, integração e adaptação ao ambiente social, onde a ciência positiva apontem caminhos à crescente adaptação social e civilidade (SARMENTO, 2008).

"Os tratados internacionais voltados à proteção dos direitos humanos, ao mesmo tempo em que afirmam a personalidade internacional do indivíduo e endossam a concepção universal dos direitos humanos, acarretam aos Estados que os ratificam, obrigações no plano internacional" (PIOVESAN, 2014, p.75). Com isso, pode-se dizer que a partir da teoria do fato jurídico e seus planos, percebe-se sua preocupação com a adaptação social sob um prisma de justiça e efetivação de direitos, a fim de salvaguardar a dignidade da pessoa humana, e a partir isso, analisarse-á a incidência dos tratados de Direitos Humanos no direito brasileiro sob o conceito de regra jurídica proposto. 


\section{A CONSTRUÇÃO DA NORMATIVIDADE JURÍDICA DOS TRATADOS DE DHS, DENTRO DA TEORIA DO FATO JURÍDICO}

A concepção do ser humano para Pontes de Miranda é fato jurídico stricto sensu. A partir deste fato jurídico não se irradia o efeito de personificação, havendo a possibilidade de prole (persona futura) como elemento de suporte fático de alguns fatos jurídicos (1954 b).

Regra jurídica em seu conceito é norma com que o homem, ao querer subordinar os fatos a certa ordem e a certa previsibilidade, procurou distribuir os bens da vida (MIRANDA, 1954). Para Miranda, há o fato de legislar, que é editar a regra jurídica, há o fato de existir, despregada do legislador, a regra jurídica, há o fato de incidir o que ela prevê, e regula. "O que é por ela previsto e sobre o qual ela incide é o suporte fático, conceito da mais alta relevância para as exposições e as invenções científicas" (MIRANDA, 1954, p.2).

A regra jurídica foi a criação mais eficiente do homem para submeter o mundo social, e os homens às mesmas ordenação e coordenação a que ele como parte do mundo físico e submete. O mundo jurídico leva consigo muito de imitação do natural, de modo que a vida inter-humana regrada faz um todo físico, vital, psíquico, dito social, em que as determinações se entrelaçam, com as incidências das regras jurídicas colorindo fatos à medida que se produzem, persistem, desaparecem ou se extinguem. A proposta dos planos e a caracterização do suporte fático também se embasam na perspectiva legalista do Direito e na sua cientificidade, pois para Pontes, um fato social apenas ingressa no mundo jurídico quando se enquadra no suporte fático previamente especificado na lei, no Código (ENGELMANN, 2011, p.4).

Como já mencionado, Pontes chamou a incidência de regra jurídica de respeitabilidade, e com este pensamento tentou e continua através de sua teoria, chegar a soluções para o problema social das pessoas. O debate acerca dos Direitos Humanos tem se intensificado em todo o mundo a partir de violações a tratados internacionais de todos os segmentos. A incidência das regras jurídicas proposta pelo autor estudado coloca que ainda há lugar e tempo para a incidência da regra jurídica, 
ela é fato no espaço e no tempo, a sua incidência situa-se no espaço e no tempo. Se esta premissa é verdadeira, a ratificação de tratados internacionais pelo Brasil, por exemplo, deve ser considerada como primordial para teoria, já que os fatos sociais existem e necessitam de uma regulamentação eficaz.

A normatividade internacional de proteção dos direitos humanos, conquistada através de incessantes lutas históricas, e consubstanciada em inúmeros tratados concluídos com este propósito, foi fruto de um lento e gradual processo de internacionalização e universalização desses mesmos direitos (MAZZUOLI, 2001, p.212). O intuito desta legislação foi o reforço à concepção da necessidade de relativização da soberania dos Estados após a primeira Guerra Mundial, da Liga das Nações, cuja finalidade era de promover a cooperação, paz e segurança internacional. A OIT (Organização Internacional do Trabalho) teve grande importância na consolidação e formação do direito internacional dos direitos humanos.

Da mesma forma que ocorre com o sistema de proteção global, existem instrumentos de alcance geral - os que abrangem todas as pessoas- e especial- são os que visam apenas determinados sujeitos de direito, ou determinada categoria de pessoas como: idosos, crianças, grupos étnicos, refugiados, deficientes e etc.

O Direito Internacional dos direitos humanos como ramo do Direito Internacional Público emerge de princípios próprios, autonomia e especificidade além de apresentar hierarquia constitucional, suas normas passam a ter característica da expansividade decorrente da abertura de seus enunciados. Ainda, rompem com a distinção rígida entre o público e o privado (MAZZUOLI, 2001).

O que interessa é dizer que o fato da regra jurídica existir no mundo das relações humanas, e do pensamento humano, e o fato de se comporem suportes fáticos e o fato da incidência, tudo leva a tratar os problemas do direito vendo-os no mundo dos fatos seguido do mundo jurídico que é parte dele. Neste sentido, pode-se dizer que os tratados de direitos humanos inserem-se no contexto de regra jurídica pelo simples fato de sobrevir a duas grandes guerras e demonstrar clara preocupação com a situação da pessoa humana. 
Para Douzinas, as lutas por direitos humanos são simbólicas e políticas, pois seu campo de batalha é o significado de palavras, tais como diferença, igualdade ou semelhança e liberdade, mas, se bem- sucedidas elas acarretam conseqüências ontológicas, transformam radicalmente a constituição do sujeito jurídico e afetam a vida das pessoas (2009, p.265).

O mundo jurídico confina segundo Miranda, com o mundo dos fatos (materiais, ou enérgicos, econômicos, políticos, de costumes, morais, artísticos, religiosos, científicos), donde as múltiplas interferências de um no outro. Segundo Pontes, o mundo do direito deveria se render a outras áreas, as quais pudessem dirimir questões importantes ao mundo jurídico. Segundo Saramago, o Sistema de Direito Positivo concebido por Pontes de Miranda não se restringia ao normativismo, mas acreditava que todos os ramos do saber eram úteis para a ciência do direito. $O$ jurista não poderia desprezar os indicativos de outras ciências na formulação do direito positivo (SARAMAGO, 2010, p.259). Fato jurídico provém do mundo fático, porém, nem tudo que o compunha entra, sempre, no mundo jurídico.

O estudo dos fatos jurídicos, a partir de revisão dos processos lógicos e metodológicos empregados para se classificarem os fatos jurídicos, devem verificar que os fatos jurídicos são quaisquer fatos, ou suportes fáticos, que entrem no mundo jurídico, sem contar com a exclusão de fatos contrários a direito. Para Del' Olmo, as fontes do Direito podem ser materiais: fatores sociológicos, econômicos, e culturais, entre outros, que conduzem à instituição da norma jurídica; e formais: as regras jurídicas elaboradas por processo legislativo, os costumes, a analogia e os princípios gerais do Direito (DEL' OLMO, 2014).

Dentre as mudanças mais significativas no âmbito dos direitos humanos encontram- se a possibilidade de os juízes exercerem o controle de constitucionalidade das leis com base na Convenção Europeia de Direitos Humanos, além de indícios de desenvolvimento de um sistema monista, no que se refere à Convenção, em países tradicionalmente dualistas (como o Brasil) e a modificação das visões tradicionais de separação de poderes no que se refere ao papel do judiciário. 
A respeito da pluralidade das regras jurídicas importa colocar a importância do estudo de recepção de outros institutos pelo direito brasileiro. Para Bragato, com a afirmação do Direito Internacional dos direitos humanos na segunda metade do século $\mathrm{XX}$, baseado no princípio da mesma dignidade dos seres humanos, que reconhece e celebra a diversidade de cada ser humano, a igualdade e a não discriminação tornaram-se seus elementos fundamentais (2013, p.78).

Diz-se que $o$ ato humano- ato-fato- humano é o fato produzido pelo homem e nem sempre estão de acordo com a vontade do homem. "Se o direito entende que é relevante essa relação entre o fato, a vontade e o homem, que em verdade é dupla (fato, vontade-homem), o ato humano é ato jurídico, lícito ou ilícito, e não ato- fato, nem fato jurídico stricto sensu"(MIRANDA, 1954. p.372-373).

Na especificação, o suporte fático há de conter a formação de novas espécies, coisa nova, pelo ato de se elaborar com uma, ou mais matérias, ou de se transformarem duas ou mais matérias ou uma só. O conceito de novo é o da vida de todos os dias: supõe, apenas, que se reconheça o elemento trabalho humano.

O mundo social é o círculo, porque é dentro de cada grupo que se opera a evolução. Nunca nos esqueçamos de que os círculos sociais são sistemas mais ou menos fechados, que livram, da dura seleção os membros que os compõem, e em que é possível a intervenção eficaz, a fim de substituir à violenta equação correspondente ao processo biológico da luta pela vida o processo sociológico do maior aproveitamento de valores, segundo o critério, não somente vital, mas social, de adaptação. "No terreno do direito, opera-se de modo tão característico a evolução que muitas regras não só desaparecem das legislações e dos códigos, como se integram os próprios movimentos e na estrutura orgânica da sociedade"(MIRANDA, 1983, p.190).

Segundo Del'Olmo, existem divergências quanto às fontes, mas em essência as classificam em fontes internas: leis de cada país; e fontes externas: os tratados. Nos dois pólos encontram-se os costumes, a doutrina e a jurisprudência (2014, p.29). A lei é a principal fonte de Direito Internacional Privado na maioria dos países, encontrada em seus Códigos Civis ou em leis especiais. No Brasil, ela detém essa 
primazia como fonte de Direito Internacional Privado contida em várias normas jurídicas. Para Piovesan, os tratados são acordos internacionais celebrados entre sujeitos de Direito Internacional, sendo regulados pelo regime jurídico do Direito Internacional (PIOVESAN, 2010, p.105).

A Constituição de 1988 apresenta em seu texto postulados referentes à estrangeiros, extradição, homologação de sentença estrangeira. A Lei de introdução às Normas do Direito Brasileiro (LINDB) traz normas sobre o conflito de leis no espaço, seguida pelo Estatuto do Estrangeiro.

A respeito dos tratados, versa a Convenção de Viena sobre o Direito dos Tratados, a qual teve como preocupação definir o que se entende por tratado e sua finalidade, pois havia a necessidade de disciplinar e regular o processo de formação dos tratados internacionais, resultando nesta carta que teve por finalidade servir como a Lei dos Tratados (PIOVESAN, 2014). Pode-se dizer que o tratado, acordo internacional celebrado por escrito entre Estados e regido pelo Direito Internacional visa produzir efeitos jurídicos entre as partes contratantes (MAZZUOLI, 2002, p.19), e, na impossibilidade de uma lei supranacional com poder de coerção sobre os países, os tratados assumem excepcional importância, pois uma vez promulgado, passa o tratado a ter força de lei. No Brasil, o tratado deve ser aprovado pelo Legislativo e promulgado pelo Presidente da República, necessitando, ainda de troca de cartas de ratificação.

O Supremo Tribunal Federal já consagrou a teoria da paridade entre o tratado e a lei nacional, de modo que o tratado prevalece sobre as leis internas anteriores à sua promulgação. A Emenda Constitucional ํo 45 de 2004, inseriu o §3ำ no artigo 5, determinou que os tratados e convenções internacionais sobre direitos humanos quando forem aprovados, em cada casa do Congresso Nacional, em dois turnos, por três quintos dos votos dos respectivos membros, serão equivalentes às emendas constitucionais (DEL'OLMO, 2014).

O artigo 5으, parágrafo $2^{\circ}$ da Constituição de 1988 inovou ao prever a incorporação dos direitos reconhecidos em tratados internacionais, embora o STF mantivesse a jurisprudência firmada sob o regime da Constituição de 1969, segundo 
a qual os tratados possuiriam o mesmo nível hierárquico das leis ordinárias. Nota-se que antes de 1988, o STF havia firmado o entendimento de que os tratados internacionais incorporam-se ao direito interno no mesmo nível das leis, podendo ser revogados por lei posterior ou deixar de ser aplicados em favor de lei específica.

Os julgados do STF sobre a matéria não diziam respeito aos direitos humanos e a menção aos tratados feita pelo artigo $5^{\circ}$, parágrafo $2^{\circ}$ da Constituição de 1988 , criou a expectativa onde a ratificação desses instrumentos internacionais pelo Brasil pode provocar mudança no entendimento do STF. Na ADIn № 1.480 (1997), o tribunal reafirmou que não apenas os tratados internacionais estão subordinados à Constituição, como também se situam no mesmo plano de validade, eficácia e autoridade das leis ordinárias (MAUÉS, 2013).

Com a promulgação da Emenda Constitucional ํo 45, acrescentou-se três disposições sobre direitos humanos, são elas: a previsão de incorporação dos tratados internacionais de direitos humanos com status de emendas constitucionais (desde que aprovados pelo mesmo quórum mínimo exigido), a constitucionalização da adesão do Brasil ao Tribunal Penal Internacional, e a criação do incidente de deslocamento de competência para a justiça federal nos casos de grave violação dos direitos humanos. Dessa forma, o parágrafo $3^{\circ}$ teria vindo reforçar a constitucionalidade dos tratados de direitos humanos, uma vez que não seria razoável colocar em níveis hierárquicos distintos tratados que dispõem sobre a mesma matéria (MAUÉS, 2013, p.218).

A tese da supralegalidade foi a posição adotada no STF, e, as razões apresentadas em favor dessa decisão, podem ser destacadas da seguinte forma: em primeiro lugar a supremacia formal e material da Constituição sobre todo o ordenamento jurídico, consubstanciada na possibilidade de controle de constitucionalidade inclusive dos diplomas internacionais; o risco de uma ampliação inadequada da expressão "direitos humanos", que permitiria uma produção normativa alheia ao controle de sua compatibilidade com a ordem constitucional interna; e o entendimento que a inclusão do parágrafo $3^{\circ}$ do artigo $5^{\circ}$ implicou reconhecer que os tratados ratificados pelo Brasil antes da Emenda ํㅡ 45 não podem ser comparados às normas constitucionais. A partir da adoção da tese da supralegalidade verifica-se que 
esses precedentes se consolidam e novos precedentes são estabelecidos, utilizando os tratados de direitos humanos, especialmente a Convenção Americana de Direitos Humanos, para interpretar a Constituição [...] (MAUÉS, 2013, p.220).

Nota-se que a tendência contemporânea do constitucionalismo mundial de prestigiar as normas internacionais destinadas à proteção dos direitos humanos, sob a evolução do sistema interamericano de proteção dos direitos humanos e os princípios do direito internacional no tocante ao cumprimento de obrigações internacionais não permitem mais a manutenção da tese da legalidade, neste caso, a supralegalidade seria uma solução para compatibilizar a jurisprudência do STF com essas mudanças, sem os problemas que seriam decorrentes da tese da constitucionalidade. Assim, os tratados de direitos humanos passam a paralisar a eficácia jurídica de toda e qualquer disciplina normativa infraconstitucional com eles conflitante.

Na ausência de previsão constitucional sobre a hierarquia dos tratados, esses podem vir a adquirir nível constitucional e serem aplicados diretamente em virtude de diferentes regras de interpretação constitucional, tais como aquelas que prevêem que os direitos declarados na Constituição devem ser interpretados de acordo com os instrumentos internacionais; as que estabelecem uma orientação geral para a atuação dos órgãos do Estado com relação ao respeito e garantia dos direitos humanos; e as que estabelecem que os direitos humanos sejam interpretados com base no princípio da progressividade, segundo o qual não se admite interpretação que resulte em diminuição de seu gozo, exercício e proteção efetivos (MAUÉS, 2013, p.225).

O diálogo entre as fontes do Direito, no qual se busca a noção de regra jurídica para as demais fontes, além do texto da lei, quer dizer, juridicizar fatos sem estarem previstos especificamente nos textos legais, com isso, pode-se dizer que a recepção dos tratados internacionais pelo Brasil pode sim, estar de acordo com o conceito de regra jurídica estudado por Pontes no momento em que há um tratamento adequado para a recepção destas regras e se constituem como complemento da legislação interna. 


\section{AS NORMAS DE DIREITOS HUMANOS NO BRASIL NO PLANO DA VALIDADE DE PONTES DE MIRANDA}

A internacionalização dos direitos humanos constitui um movimento surgido com o pós-guerra, advindo dos acontecimentos monstruosos como o nazismo. Em 10 de dezembro de 1948 foi aprovada a Declaração Universal dos Direitos Humanos, a qual traz em seu texto a concepção contemporânea de direitos humanos: universalização e indivisibilidade de direitos. Os direitos definidos na Declaração de 1948 correspondem, integralmente, ao que o costume e os princípios jurídicos internacionais reconhecem como normas imperativas de direito internacional geral (COMPARATO, 2007, p.227). A partir deste texto, as preocupações foram de converter os direitos humanos em tema legítimo de interesse da comunidade internacional.

A consolidação dos direitos humanos através deste processo permitiu a formação de uma rede de proteção internacional destes direitos, o que significou uma evolução do direito interno ao recepcionar normas de direito Internacional. "Pode se dizer que na era das Nações Unidas consolidou-se, paralelamente o sistema de segurança coletiva, que, no entanto, deixou de operar a contento em razão dos impasses gerados pela guerra fria" (TRINDADE, 2006, p.110).

Com a formação do sistema normativo global de proteção dos direitos humanos no âmbito das Nações Unidas coloca-se a integração por instrumentos de alcance geral como Pactos e de interesses específicos como as Convenções Internacionais, as quais buscam dirimir violações como: discriminação, tortura e outras formas de violações.

Se os planos de Pontes de Miranda e a caracterização do suporte fático se encontram alicerçadas na perspectiva legalista do Direito e na sua cientificidade, pois para ele um fato social apenas ingressa no mundo jurídico quando se enquadra no suporte fático previamente especificado na lei, no código, veja como esta teoria pode ter incidência na recepção dos tratados de direitos humanos. A regra jurídica está catalogada com um elemento fundamental na caracterização do Direito, que se 
entende como um 'dever ser', ou seja, que algo deve acontecer, ou que alguém deve conduzir-se de determinada maneira (ENGELMANN, 2011, p.6).

O Sistema Americano de Direitos Humanos tem como principal instrumento a Convenção Americana de Direitos Humanos de 1969, a qual estabelece a Comissão Interamericana de Direitos Humanos e a Corte Interamericana, constituindo um sistema regional de proteção de direitos o qual se complementa com o sistema global (PIOVESAN, 2014).

No caso brasileiro, a Constituição de 1988 determina que seja da competência privativa do Presidente da República celebrar tratados, convenções e atos internacionais (art. 84 VIII) e segundo a Emenda Constitucional n 45, aprovada no ano de 2004, prevê no $3^{\circ}$ que os tratados e convenções internacionais sobre direitos humanos que forem aprovados, em cada Casa do Congresso Nacional, em dois turnos, por três quintos dos votos dos respectivos membros, serão equivalentes às emendas constitucionais. Ainda, por força do artigo $5^{\circ} \S 1^{\circ}$, prevê- se que os tratados tem aplicação imediata. Para Mazzuoli (2002), a constituição de 1988, seguindo a tendência do constitucionalismo contemporâneo de se igualar hierarquicamente os tratados de proteção dos direitos humanos às normas constitucionais deu grande passo rumo a abertura do sistema jurídico brasileiro ao sistema internacional de proteção aos direitos entendido no artigo $5^{\circ} \S^{2}{ }^{\circ}$ da CF/88.

A Constituição estabelece que direitos e garantias nela elencados não excluem outros provenientes dos tratados internacionais em que a República Federativa do Brasil seja parte (art. $5 \S 2^{\circ}$ ), é porque ela própria está a autorizar que esses direitos e garantias internacionais constantes dos tratados internacionais ratificados pelo Brasil "se incluem" no nosso ordenamento jurídico interno, passando a ser considerados como se escritos na Constituição estivessem. É dizer, se os direitos e garantias expressos no texto constitucional "não excluem" outros provenientes dos tratados internacionais em que o Brasil seja parte, é porque, pela lógica, na medida em que tais instrumentos passam a assegurar certos direitos e garantias, a Constituição "os inclui" no seu catálogo de direitos protegidos, ampliando assim, o seu bloco de constitucionalidade. 
Ao incorporar seu texto no direito internacional, está a Constituição atribuindoIhes natureza especial e diferenciada, a natureza de norma constitucional, o qual passa a integrar o rol dos direitos constitucionalmente protegidos. Qual seja a Constituição além de incorporar valores provenientes de tratados internacionais thes dá juridicidade, na medida em que Ihes reconhece como fazendo parte do direito constitucional efetivamente válido. Deixando claro que estas normas não possuem caráter infraconstitucional, pois possuem função de proteger e promover a dignidade da pessoa humana, complementando o rol dos direitos e garantias e ampliando o núcleo de direitos. "O ciclo das Conferências Mundiais das Nações Unidas deste final de século tem procedido a uma reavaliação global de muitos conceitos à luz da consideração de temas que afetam a humanidade como um todo" (TRINDADE, 2006, p.110).

A respeito da validade na incorporação dos tratados, Pontes de Miranda coloca que para que o ato jurídico possa valer, é preciso que o mundo, onde deu entrada, o tenha por apto a nele atuar e permanecer, e neste momento, vai se exigir a eficiência, pois seus efeitos irão se "irradiar" (MIRANDA, 2000, p.2).

A evolução humana, segundo Miranda, é a maior adaptação dos indivíduos entre si: daí resulta diminuição do despotismo, redução das assimetrias, tais como as classes sociais. Ainda, que a maior liberdade provoca maior igualdade e sendo assim, maior igualdade provoca maior liberdade. Pode-se, por outro lado, verificar que em um processo democrático há necessidade de liberdade, assim como a liberdade precisa de democracia e ambas de igualdade. A liberdade cresce na razão inversa do despotismo, da vontade de um ou de alguns, ou de muitos, e na razão direta da intervenção de julgamentos de fato e critérios de verdade: a democracia pode levar ao despotismo, mas as probabilidades são menores.

Para Pontes, o grande mal do público, no século $X X$, com a sua preocupação absorvedora do imediato e do prático, está em crer que as convicções filosóficas, metafísicas, ou as tendências emocionais, não são causa de atitudes decisivas na vida e nas instituições. Segundo ele, no mesmo tempo em que se faz a análise das 
almas e comportamentais, seja tão discrepante descrer de causação entre o interior e o exterior dos homens.

Acerca das liberdades, o estado de espírito em muitos países de governos fortes teve, por um período, uma reflexão e elaboração de leis honestamente mais favoráveis ao homem comum. Nestes períodos, é importante salientar, os grupos internacionais colocam os perigos de se conservar a liberdade. A partir deste pensamento, "a liberdade é garantida se e enquanto não se cogita de melhorar a situação de classes favorecidas" (MIRANDA, 1979, p.256), com isso, o espírito democrático segue ameaçado, de modo que a Constituição, inconscientemente, passe a incorporar valores sociais básicos.

A igualdade pode ser considerada como processo social, o qual interage aos poucos, e segundo Pontes, não pode ocorrer com a mesma rapidez com que obteve a liberdade pela razão de que os homens não estão preparados para ela e não são capazes de assegurá-la. "Convencer em vez de vencer" (1979, p.258), pois toda a democracia sã tende a isso, pois dentro da condição humana, o de poder corrigir o erro de um, ou de alguns, com a crítica de todos. A maior igualdade serve para pensar no outro, pensando-se em todos, pensa-se em si mesmo e pensa-se nos outros.

Ao se pensar no contexto brasileiro, pode-se colocar que a luta pela liberdade começou cedo e não se pode dizer que o povo não lutou, lutou e foi infeliz. Perdeu sempre, ou venceu sempre, ou venceu por pouco, e não foi insignificante.

O ordenamento jurídico somente atribui validade ao ato jurídico que corresponde a suporte fático que é suficiente e eficiente, isto é, suficiente e nãodeficiente ou não deficitário, isto é, suficiente. Os pressupostos de validade apontados por pontes são: ao sujeito do ato jurídico que consentem ou devem assentir; ao objeto do ato jurídico; a elementos do ato jurídico relativos. Toda validade se liga ao momento em que se faz jurídico o suporte fático, pois toda eficácia será produção da juridicidade do fato jurídico (MIRANDA, 2000, p. 16).

A categoria desenvolvida por Pontes de Miranda é um tipo que fica entre ato e fato, e consiste em um comportamento que mesmo sendo proveniente da atuação 
humana é desprovido de consciência. Os elementos da validade é que qualificam o negócio jurídico.

No tocante ao plano da validade, o ato jurídico pode ser latu sensu, onde a presença da ação humana no núcleo do suporte fático pode contaminar o ato jurídico latu sensu com isso, o referido ato sai do plano da existência e vai para o plano da validade. Seja ele strictu sensu ou negócio jurídico, será analisado sob o aspecto do sujeito, objeto e forma. Se ele for válido, produz efeito, como já mencionado, se não, será obstacularizado, pois não produz efeito imediato, embora mais tarde possa vir a subir ao plano da eficácia, ou seja, ser eficaz. Quando o ato jurídico vai para o plano da validade, é feita a análise de sua eficiência, se foram observados seus pressupostos ou deficiências. Todo ato jurídico, para ser válido, tem que ser realizado por agente capaz. A validade também depende da licitude do objeto. O objeto significa objetivo, é finalidade. Todo ato jurídico latu sensu tem forma livre, salvo se a norma jurídica estabelecer outra coisa. A invalidade pode ser considerada como gênero. No mundo fático, não há nulidades, nem anulabilidades. No próprio mundo jurídico semente há nulidades e anulabilidades de negócios jurídicos e de atos jurídicos stricto sensu.

Tratados internacionais enquanto acordos, juridicamente obrigatórios e vinculantes constituem a principal fonte de obrigação do Direito internacional. $\mathrm{Na}$ reivindicação de seus direitos, a pessoa humana é sujeito do direito interno assim como do direito internacional, dotada em ambos de personalidade e capacidade jurídicas. Em última análise, a primazia é sempre da norma que melhor proteja (TRINDADE, 2006).

Faz-se importante perceber o valor dos direitos humanos na sociedade moderna e a importância a sua adequação a teorias como a de Pontes de Miranda. A importância a que os Estados tem de compatibilizar os comandos do produto normativo com normas de direito interno permitem que o ordenamento jurídico em detrimento de determinado país demonstre sua índole constitucional. Se para Pontes a importância da evolução humana era peça chave em suas teorias as adaptações as normativas regras de direito se fazem de suma importância. 


\section{A CORTE INTERAMERICANA DE DIREITOS HUMANOS E SEUS JULGADOS}

Pontes de Miranda demonstrou uma teoria dos direitos, a teoria do fato jurídico, de grande importância para o Brasil, e com isso, de certa forma, garantiu o comprometimento dos governos com a efetivação de direitos, bem como dos direitos humanos, a fim de promover o desenvolvimento e a justiça social. Segundo sua teoria, a humanidade dependia da substituição do Estado pelo equilíbrio entre fatores como: democracia, liberdade e igualdade. Ele compreendeu que isso só seria possível a partir da consolidação dos direitos humanos através dos tratados internacionais e da constituição. Menciona George Sarmento que "[...] a característica material mais acentuada das normas jurídicas é a força de incidência, através da qual se opera a transformação do suporte fáctico em fato jurídico" (SARMENTO, 2005, p.7).

Com relação aos direitos e garantias fundamentais, apresentam-se duas linhas: a supra-estatal que nada mais é do que o direito internacional, e a estatal a qual se refere aos direitos internos do estado nacional. A ordem jurídica supra-estatal disciplina desde a criação de novos Estados até a previsibilidade das relações que se travarão entre eles. O mesmo acontece com a ordem interna, que vai da Constituição até o mais simples ato estatal (legislativo, administrativo ou judicial) (SARMENTO, 2005, p.2).

Direitos fundamentais estatais são de grande importância para o fortalecimento do Estado Democrático de Direito na teoria de Pontes de Miranda, pois podem ser considerados como um ponto de equilíbrio na evolução de grandes nações, pois é possível verificar a partir deles o nível de desenvolvimento da liberdade, igualdade, solidariedade e democracia nos ordenamentos de cada Estado (MIRANDA, 1979).

Acerca da supralegalidade de direitos, pode-se mencionar que são provenientes da ordem jurídica internacional. Estão contidos na Declaração Universal dos Direitos do Homem (1948), nos pactos que a regulamentaram e especialmente na Convenção Americana de Direitos Humanos, chamada de Pacto de San José da Costa Rica (CADH) de 1.969 a qual será tratada neste ponto. A incidência destas leis não depende apenas de reconhecimento constitucional, já que pertencem à ordem 
jurídica exterior e acima do Estado, mas de todo o ordenamento. Em relação a eles, o Estado atua como definidor de exceções e clarificador de conteúdo pela mediação do legislador constituinte ou ordinário. Para Sarmento,"os direitos fundamentais supra-estatais são paradigmas de validade das normas de direito interno, inclusive das normas constitucionais".

Normas jurídicas podem ser consideradas como meio para a realização do direito como processo de adaptação social, as quais são capazes de criar um fenômeno jurídico, pois sem ela não se pode falar de direitos, mas de aspirações sociais ou valores éticos. Os direitos fundamentais supra-estatais são paradigmas de validade das normas de direito interno, inclusive das normas constitucionais.

É preciso delimitar algumas reflexões e com isso, faz-se importante o entendimento acerca dos trâmites necessários para recepção de um tratado. Iniciamse as negociações internacionais preliminares através do Chefe de Estado, ministros e diplomatas. Estes são encarregados de estudos prévios, análise de implicações jurídicas de modo a assegurar a constitucionalidade dos tratados, convenções e outros documentos internacionais. Assim, a celebração de tratados é competência exclusiva do Presidente da República, conforme menciona o artigo 84 VIII, da Constituição Federal do Brasil.

Contudo, firmado o tratado, o Presidente encaminhará ao Congresso Nacional, acompanhada de exposição de motivos, para ser apreciada pela Câmara dos Deputados e pelo Senado Federal, conforme mencionam os artigos 64 e 65 da Constituição. A discussão da matéria se dá na Comissão de Relações Exteriores, seguida pela Comissão de Constituição e Justiça e de Redação sendo dirigida para as comissões temáticas da Câmara dos Deputados, terminando em plenário. Após, enviado ao Senado Federal, o projeto de decreto legislativo será debatido na Comissão de Relações Exteriores e Defesa Nacional e plenário. O projeto só será aprovado se tiver a maioria dos votos, exigindo-se a presença da maioria dos parlamentares na sessão em ambas as casas.

Obtida a aprovação das casas, o Presidente do Senado editará decreto legislativo autorizando o Presidente a ratificar o tratado, contudo, a autorização não 
obriga o Chefe do Executivo a fazê-lo, e não assegura vigência do tratado, ele permite que se promulgue e publique o decreto presidencial no Diário Oficial da União. Havendo entendimento contrário onde o Presidente desista ou se negar a ratificá-lo, o tratado não terá aplicabilidade interna. Sendo assim, a ratificação, conditio sine qua non de vigência do tratado no direito interno. Por fim, será feito o depósito do ato nos órgãos internacionais competentes. A ratificação dos tratados é ato discricionário e irretratável, é manifestação expressa do compromisso estatal de executar em seu território normas jurídicas de direito internacional. A partir da promulgação, o tratado entra em vigor e pode ser aplicado em todo o país e sua incorporação no sistema jurídico brasileiro se dá em forma de lei ordinária, submetendo-se, portanto, a controle de constitucionalidade.

Mas ainda assim, existia uma lacuna a qual representava um atraso que precisava ser corrigido urgentemente pela técnica da recepção formal dos tratados. Essa medida seria um grande salto evolutivo na proteção dos direitos humanos no Brasil, ocorrendo apenas no ano de 2004, onde, a Emenda Constitucional ํo 45 foi aprovada, introduzindo o parágrafo $3^{\circ}$ ao artigo $5^{\circ}$ da Constituição Federal do Brasil.

A partir de então, há a possibilidade de recepção constitucional de tratados internacionais sobre direitos humanos mediante processo legislativo especial, onde é necessário que a matéria seja discutida e aprovada em dois turnos pela Câmara dos Deputados e pelo Senado Federal, sendo aprovada em ambos, necessitando esta ter a aprovação de quorum qualificado de $3 / 5$ dos membros de cada Casa do Congresso Nacional.

Os tratados e documentos de proteção aos direitos humanos passaram a ser incorporados com mais intensidade nas Constituições a partir da criação da Organização das Nações Unidas no ano de 1945 e da Organização dos Estados Americanos de 1948. Após, outras organizações regionais, como a União Européia e o Mercosul se sensibilizaram. Importante salientar que o documento mais importante produzido pela OEA foi, a Convenção Americana de Direitos Humanos datada de 1969, mais conhecida como Pacto de São José da Costa Rica, (ratificada pelo Brasil 
em 25 de setembro de 1992), pois além de proclamar direitos e garantias fundamentais, a Convenção criou a Corte Interamericana de Direitos Humanos.

Sobre a Corte Interamericana de Direitos Humanos, esta pode ser definida como um órgão judicial autônomo com sede em San José da Costa Rica, a qual possui o propósito de aplicar e interpretar a Convenção Americana de Direitos Humanos e outros tratados de Direitos Humanos. Ela faz parte do chamado Sistema Interamericano de Proteção aos Direitos Humanos ${ }^{1}$.

A Corte exerce competência contenciosa e consultiva. Consultiva, pois tem competência litigiosa para conhecer de qualquer caso relativo à interpretação e aplicação das disposições da Convenção Americana de Direitos Humanos a que the seja submetida apreciação, sempre que os Estados signatários reconheçam esta competência, por declaração ou convenções especiais. Conhece os casos em que se diga que um dos Estados-membros tenha violado um direito ou liberdade protegido pela Convenção, com isso, sendo necessário que se tenham esgotados os seus procedimentos.

A função Contenciosa da Corte determina que nos casos submetidos à sua jurisdição, se um Estado incorreu em responsabilidade internacional pela violação de algum direito reconhecido na Convenção Americana ou em outros tratados de direitos humanos aplicáveis ao sistema interamericano este dispõe de medidas necessárias para reparar as conseqüências derivadas da vulneração de direitos. O Tribunal deve realizar a supervisão de cumprimento de suas próprias sentenças. Com isso, o procedimento seguido pelo Tribunal para resolver os casos contenciosos submetidos à sua jurisdição possui duas fases: a contenciosa, onde se dá a apresentação do caso pela Comissão, em seguida a apresentação por escrito das solicitações, argumentos e provas por parte das supostas vítimas, também a apresentação do escrito de contestação aos dois escritos anteriores por parte do Estado demandado, após os escritos de contestação às exceções preliminares interpostas pelo Estado, no caso de que corresponda seguido do escrito de lista definitiva de declarantes e por fim a resolução de convocatória a audiência. Segundo esta primeira etapa se dá a etapa

${ }^{1}$ Sistema Interamericano de Direitos Humanos. CIDH, 2006. 
oral ou de audiência pública, após a etapa de escritos de alegações e observações finais das partes e da Comissão, então a etapa de estudo e emissão de sentença. A segunda fase é a de Supervisão de cumprimento de sentenças².

A fase contenciosa se inicia com o envio do caso à Corte, seguindo do pressuposto que e as partes contem com toda a informação necessária para a adequada tramitação do processo. Exige o regulamento da Corte que a apresentação do caso inclua, entre outros aspectos: a) os motivos que levaram a Comissão a apresentar o caso; b) uma cópia do relatório emitido pela Comissão previsto no artigo 50 da Convenção Americana; e c) uma cópia da totalidade do expediente de trâmite perante a Comissão, incluindo toda comunicação posterior ao relatório do artigo $50 \mathrm{da}$ Convenção. Uma vez apresentado o caso, a Presidência realiza um exame preliminar do mesmo para comprovar que tenham sido cumpridos os requisitos essenciais de apresentação. Em caso afirmativo, a Secretaria notifica o caso ao Estado demandado e à suposta vítima, a seus representantes, ou ao Defensor Público Interamericano, se for este o caso.

O procedimento feito pela Corte possui caráter contraditório, pois se encerra com sentença judicial motivada, obrigatória, definitiva e inapelável. Caso haja desacordo sobre o sentido ou alcance da decisão, a Corte o interpretará por solicitação de qualquer das partes, sempre que esta solicitação seja apresentada dentro de noventa dias a partir da notificação da sentença.

Sobre a Competência consultiva, ainda, os Estados-membros da OEA podem consultar a Corte sobre sua interpretação da Convenção Americana de Direitos Humanos ou de outros tratados concernentes à proteção dos Direitos Humanos no âmbito dos Estados Americanos, que podem consultá-la, dentro de sua competência, bem como os órgãos da Organização dos Estados Americanos. Pode ainda, a pedido de um Estado-membro da OEA, emitir parecer sobre a compatibilidade entre qualquer de suas leis internas e os mencionados tratados internacionais. A Corte é composta por sete juízes pertencentes aos Estados-membros da OEA, eleitos a título pessoal entre juristas da mais elevada autoridade moral, de reconhecida competência em

2 Texto do site da Corte Interamericana de Direitos Humanos. 
matéria de Direitos Humanos, os quais reúnam as condições requeridas para o exercício das mais elevadas funções judiciais conforme da lei do país do qual seja nacional ou do Estado que Ihe proponha a candidatura. Importante ressaltar que não pode haver mais de um juiz da mesma nacionalidade.

A Convenção consagra direitos civis e políticos, bem como o direito ao reconhecimento da personalidade jurídica, o direito à vida, direito à integridade pessoal, direito à liberdade pessoal e garantias judiciais, direito à proteção da honra e reconhecimento à dignidade, à liberdade religiosa e de consciência, à liberdade de pensamento e de expressão, e livre associação. Os Estados signatários da Convenção se a respeitar os direitos e liberdades nela reconhecidos e a garantir seu livre e pleno exercício a toda pessoa que esteja sujeita à sua jurisdição, sem discriminação alguma por motivo de raça, cor, sexo, idioma, religião, opiniões políticas ou de qualquer outra natureza, origem nacional ou social, posição econômica, nascimento ou qualquer outra condição social, conforme coloca seu artigo 103 .

Se o exercício de direitos e liberdades não for assegurado na legislação ou outras disposições, os Estados membros estão obrigados a adotar as medidas legais ou de outro caráter para que estes direitos venham a tornar-se efetivos. Piovesan comenta que ao lado do sistema geral de proteção, organiza-se o sistema especial de proteção, que adota como sujeito de direito o indivíduo historicamente situado, isto, é, o sujeito de direito "concreto", na peculiaridade e particularidade de suas relações sociais (PIOVESAN, 2010, p.242).

A partir destas explicações, entende-se conveniente apresentar dois julgados pela Corte Interamericana referentes a fatos ocorridos no Brasil. O primeiro denominado "O caso Ximenes Lopes x Brasil" e o segundo "O caso Gomes Lund e outros 'Guerrilha do Araguaia' x Brasil” 4 .

O caso Ximenes Lopes foi o primeiro caso brasileiro julgado pela Corte desde o reconhecimento da obrigatoriedade da competência desta pelo país, a primeira condenação do Brasil em uma instância internacional de direitos humanos e também

\footnotetext{
3 Texto do site da Corte Interamericana de Direitos Humanos.

${ }^{4} \mathrm{O}$ inteiro teor das decisões, bem como o resumo pode ser encontrado no site da CIDH. 
a primeira sentença da Corte relativa a violações de direitos de pessoas portadoras de transtornos mentais. Nesse caso a Corte condenou o Brasil pela morte violenta de Damião Ximenes Lopes, ocorrida em 4 de outubro de 1999, nas dependências da Casa de Repouso Guararapes, em Sobral, no Ceará. Na sua denúncia apresentada à Corte, a CIDH referiu-se às condições desumanas e degradantes às quais Damião teria sido submetido durante sua internação na referida instituição, que era acreditada no Sistema Único de Saúde (SUS) do governo brasileiro. Supostamente por causa dos maus tratos sofridos Damião faleceu enquanto internado para receber tratamento psiquiátrico na Casa de Repouso.

A CIDH alegou a falta de investigação e de garantias judiciais no tratamento do caso por parte do Estado, bem como a gravidade dos eventos não só pela situação de vulnerabilidade das pessoas com incapacidade mental, mas também em razão da obrigação especial do Brasil de conferir proteção às pessoas que estejam sob os cuidados de clínicas de saúde que operam em convênio com o SUS. Em sua sentença a Corte fixou a responsabilidade internacional do Brasil por violar, no caso o direito à vida, à integridade pessoal, à proteção judicial e às garantias judiciais consagradas nos artigos $4^{\circ}, 5^{\circ}, 25$ e $8^{\circ}$, da $\mathrm{CADH}$, não tendo proporcionado a família de Damião um recurso efetivo para garantir acesso à justiça, a determinação da verdade dos fatos, a investigação, a identificação, o processo e a punição dos responsáveis. Tais violações se relacionavam com o fato de Damião ter um transtorno mental e a demora do Judiciário brasileiro nos processos criminal e cível ajuizados pela família.

No caso Gomes Lund, a Corte condenou o Brasil pelo desaparecimento forçado de integrantes da Guerrilha do Araguaia durante as operações militares ocorridas na década de 1970. Essa decisão se alinha à jurisprudência da Corte, especialmente, aquela consolidada no caso Barrios Altos vs. Peru, no qual este país fora condenado pelo massacre de 15 pessoas realizado por membros das Forças Armadas peruanas. Na denúncia, a $\mathrm{CIDH}$ alegou a responsabilidade do Estado brasileiro pela detenção arbitrária, tortura e desaparecimento forçado de 70 pessoas, entre membros do Partido Comunista do Brasil (PCdoB) e camponeses, como resultado das ações conduzidas pelo Exército na região entre 1972 e 1975. A partir 
daí, solicitou a responsabilização do Brasil por não ter investigado tais violações com a finalidade de julgar e punir os respectivos responsáveis, com respaldo na Lei $n^{\circ}$ 6.683 de 28 de agosto de 1979, a chamada Lei de Anistia. Com base nessas alegações, a CIDH entendeu que o Estado violou os seguintes direitos: direito ao reconhecimento da personalidade jurídica, direito à vida, direito à integridade pessoal, direito à liberdade pessoal, direito às garantias judiciais, direito à liberdade de pensamento e expressão e direito à proteção judicial, referentes aos artigos $3^{\circ}, 4^{\circ}, 5^{\circ}$, $7^{\circ}, 8^{\circ}, 13$ e 25 da CADH.

Com base nas alegações das partes e nas provas apresentadas, a Corte concluiu que não há controvérsia quanto aos fatos do desaparecimento forçado dos integrantes da Guerrilha do Araguaia, nem da responsabilidade estatal a esse respeito. A Corte reitera que o desaparecimento forçado de pessoas constitui uma violação múltipla que se inicia com uma privação de liberdade contrária ao artigo $7^{\circ}$ da CADH. A sujeição de pessoas detidas a órgãos oficiais de repressão, a agentes estatais ou a particulares que atuem com sua anuência ou tolerância, que impunemente pratiquem a tortura ou assassinato representa, por si só, uma infração ao dever de prevenção de violações dos direitos à vida e à integridade pessoal, consagrados nos artigos $4^{\circ}$ e $5^{\circ}$ da CADH. A Corte também assevera que a prática de desaparecimento implica, com frequência, a execução dos detidos, em segredo e sem julgamento, seguida da ocultação do cadáver, com o objetivo de eliminar toda pista material do crime e de buscar a impunidade daqueles que o cometeram, violando brutalmente o direito à vida. Esse fato em conexão com a falta de investigação dos acontecimentos representa uma violação à obrigação estatal de garantir a toda pessoa sujeita à sua jurisdição a inviolabilidade da vida e o direito a não ser dela privado de forma arbitrária.

Ao realizar a leitura destes casos apresentados e julgados pela Corte, percebe-se que o Brasil caminha a passos lentos para a proteção de grupos vulnerabilizados. Os direitos humanos atuam de forma incisiva também em demandas referentes às diferenças culturais, e atacam a pobreza e a alienação, deste modo o 
conceito de igualdade é enriquecido de maneira a incluir em seu bojo a discriminação positiva e os direitos coletivos.

Enfim, se para Pontes, todo fato é, mudança no mundo, então se afirma que o mundo compõe-se de fatos, e que novos fatos se dão a partir de decisões nas quais pode-se ter esperanças de respeito e não violações de Direitos Humanos a fim de que sua legalidade seja plenamente aceita no ordenamento. A pretensão neste artigo, de realizar o estudo da Teoria das Fontes do Direito a fim de ser verificado o diálogo entre as fontes do Direito, ora, lei, doutrina, costumes fazem parte de uma sistemática a qual se perfaz o mundo jurídico.

Com isso, pode-se dizer que a Teoria do Fato Jurídico não poderá apresentar apenas uma perspectiva, mas abrir possibilidades para a valorização de outras formas de expressão jurídica. Como se verificou no estudo sobre a Convenção, a qual estabelece, ainda, a obrigação dos Estados para o desenvolvimento progressivo dos direitos econômicos, sociais e culturais contidos na Carta da OEA, na medida dos recursos disponíveis, por via legislativa ou outros meios apropriados. Como meios de proteção dos direitos e liberdades.

\section{CONCLUSÃO}

A obra de Pontes de Miranda apresenta distinções entre mundo fático e mundo jurídico, sistema jurídico, o qual concorre imensamente para clarear os assuntos e para a solução de problemas delicados que perturbavam a ciência europeia; depois, a distinção entre o plano da existência, o plano da validade e o plano da eficácia, sem a qual em tantas confusões incorrem os juristas. $O$ artigo objetivou verificar de que maneira, a proteção via legislação Constitucional de grupos minoritários poderia incorporar os Planos propostos por Pontes de Miranda a partir da Teoria do Fato jurídico.

A matriz teórica de direitos humanos conjuga liberdade e igualdade, no sentido de decorrerem de direitos concebidos como uma unidade interdependente e indivisível, em decorrência, não há como entender que há uma sucessão de fatos 
sociais e há uma interação de direitos. Assim, pode-se afirmar que a normatividade internacional de proteção dos direitos humanos, conquistada através de incessantes lutas históricas.

A ordem jurídica supra-estatal está em permanente evolução, nos últimos anos, testemunhamos muitos avanços na proteção aos direitos humanos, e durante este período, dezenas de tratados foram incorporados aos ordenamentos jurídicos de todo o mundo. Intervenções humanitárias, inspeções internacionais e outras ações destinadas à consolidação, expansão, aperfeiçoamento e efetivação dos direitos fundamentais têm sido implementadas de maneira a assegurar a proteção de grupos vulnerabilizados.

A partir do estudo da teoria de Pontes pode-se afirmar que é possível ter esperanças de que os Direitos Humanos possam ser respeitados e sua legalidade plenamente respeitada e aceita no ordenamento. A pretensão do artigo, de realizar o estudo da Teoria das Fontes do Direito a fim de ser verificado o diálogo entre as fontes, ora, lei, doutrina, costumes fazem parte de uma sistemática a qual se perfaz o mundo jurídico, e a partir disso, a Teoria do Fato Jurídico não poderá apresentar apenas uma perspectiva, mas abrir possibilidades para a valorização de outras formas de expressão jurídica. Como se verificou no estudo sobre a Corte Interamericana de Direitos e a Convenção Americana de Direitos Humanos de 1.969.

Se na concepção de Pontes, as regras jurídicas necessitam de atos para sua incidência, pode-se dizer que a recepção dos tratados de direitos humanos pela via constitucional atua no sentido de não deixar lacuna, pois estes integram o ordenamento jurídico brasileiro para auxiliar, agregar a legislação interna Estatal no tocante às violações de Direitos. Os direitos humanos atuam, deste modo, de forma incisiva também em demandas referentes às diferenças culturais, e atacam a pobreza e a alienação, deste modo o conceito de igualdade é enriquecido de maneira a incluir em seu bojo a discriminação positiva e os direitos coletivos. Importante lembrar que para Pontes a preocupação com o ser humano e sua visão de mundo, nos mais vastos campos de Estudo é de grande valor, pois o ser humano necessita se relacionar com outros ramos para a integração social, além de uma evolução jurídico- social. 


\section{REFERÊNCIAS}

BRAGATO, Fernanda Frizzo. Direitos humanos além da lógica formal do princípio da igualdade: uma leitura a partir do princípio da não discriminação. IN: STRECK, Lenio Luiz; ROCHA, Leonel Severo; ENGELMANN, Wilson. (Orgs.). Constituição, Sistemas Sociais e Hermenêutica: Anuário do Programa de Pós- graduação em Direito da UNISINOS: Mestrado e Doutorado. Porto Alegre: Livraria do Advogado, 2013. n.10.

BRASIL (Constituição, 1988). Constituição da República Federativa do Brasil de 1988. 23. ed. São Paulo: Saraiva, 2013.

COMPARATO, Fábio Konder. A afirmação histórica dos direitos humano. 5 ed. rev. e atual. São Paulo: Saraiva, 2007.

CONVENÇÃO Americana sobre Direitos Humanos. Disponível em:< http://www.cidh.org/Basicos/Portugues/c.Convencao Americana.htm>. Acesso em 16 ago. 2015.

DEL'OLMO. Florisbal de Souza. Curso de Direito Internacional Privado. 10 ed. Rio de Janeiro: Forense. 2014.

DOUZINAS, Costas. 0 fim dos direitos humanos. Tradutora Luzia Araújo. São Leopoldo: Unisinos. 2009.

ENGELMANN, Wilson. A (re)leitura da teoria do fato jurídico à luz do "diálogo entre as fontes do direito": abrindo espaços no direito privado constitucionalizado para o ingresso de novos direitos provenientes das nanotecnologias. In: STRECK, Lenio Luiz e MORAIS, José Luis Bolzan de. (Orgs.). Constituição, Sistemas Sociais e Hermenêutica: Anuário do Programa de Pós- graduação em Direito da UNISINOS: Mestrado e Doutorado. Porto Alegre: Livraria do Advogado, 2011, n.7.

O diálogo entre as fontes do direito e a gestão do risco empresarial gerado pelas nanotecnologias: construindo as bases à juridicização do risco. In: STRECK, Lenio Luiz; ROCHA, Leonel Severo; ENGELMANN, Wilson (Orgs.). Constituição, Sistemas Sociais e Hermenêutica: Anuário do Programa de Pós- graduação em Direito da UNISINOS: Mestrado e Doutorado. Porto Alegre: Livraria do Advogado, 2012, n.9, p.319-344.

MAUÉS, Antonio Moreira. Supralegalidade dos tratados internacionais de direitos humanos e interpretação constitucional. IN: SUR. Revista Internacional de Direitos Humanos / Sur - Rede Universitária de Direitos Humanos - v.10, n.18, jun. 2013 São Paulo, 2013.

MAZZUOLI, Valerio de Oliveira. Direitos humanos, Constituição e os Tratados Internacionais. São Paulo: Editora Juarez de Oliveira, 2001. 456 p. 
OEA. O que é CIDH? Disponível em: http://www.oas.org/pt/cidh/mandato/que.asp. Acesso em: 10 jul. 2015.

PIOVESAN, Flávia. Direitos humanos e o direito constitucional internacional. São Paulo. Saraiva. 2014.

. Temas de Direitos Humanos. 4 ed. São Paulo: Saraiva, 2010.

PONTES DE MIRANDA, Francisco Cavalcanti. Democracia, liberdade, igualdade: os três caminhos. 2 ed. São Paulo: Saraiva, 1979.

Sistema de Ciência Positiva do Direito: introdução à Ciência do Direito. 2 ed. Rio de Janeiro: Borsoi, 1972, tomo II.

a.Tomo I.

Tratado de Direito Privado. Parte Geral. Rio de Janeiro: Borsoi, 1954 b.Tomo II.

Tratado de Direito Privado. Parte Geral. Rio de Janeiro: Borsoi, 1954

. Tratado de Direito Privado. Validade. Nulidade. Anulabilidade. Parte Geral. Campinas: Bookseller, 2000. Tomo IV.

RELATÓRIO Anual da Corte Interamericana de Direitos Humanos 2012. Disponível em: < http://www.corteidh.or.cr/sitios/informes/docs/POR/por 2012.pdf> Acesso em 18 ago. 2015.

SARMENTO, George. Direitos Fundamentais e Técnica Constitucional: reflexões sobre o Positivismo Científico de Pontes de Miranda. IN: DIDIER JR., e Fredie e EHRHARDT JR., Marcos. Revisitando a Teoria do Fato Jurídico: homenagem a Marcos Bernardes e Mello. São Paulo: Saraiva, 2010, p.253-272.

. Pontes de Miranda e a Teoria dos Direitos Fundamentais. Revista do Mestrado em Direito. v.01, p.15 - 90, 2005. Disponível em: < http://www.georgesarmento.com.br/wp-content/uploads/2011/02/Pontes-de-Mirandae-a-teoria-dos-direitos-fundamentais2.pdf>. Acesso em 18 ago. 2015.

TRINDADE, Antonio Augusto Cançado. A humanização do direito internacional. Belo Horizonte: Del Rey, 2006. 